\title{
Perfil dos Acidentes de Trabalho Ocorridos no Município de Araçatuba- SP nos anos de 2000 e 2001
}

Eduardo Pizzatto'

Cléa Adas Saliba Garbin²

Magno Amadei ${ }^{3}$

\section{Profiles of Work Accidents Occurred at Araçatuba Municipality Between year 2000 and 2001}

'Doutorando do Programa de PósGraduação em Odontologia Preventiva e Social da Faculdade de Odontologia de Araçatuba-SP-UNESP.

${ }^{3}$ Professora Assistente Doutora da Faculdade de Odontologia de Araçatuba-SP-UNESP.

${ }^{2}$ Médico do Trabalho; Coordenador do Centro de Referência em Saúde do Trabalhador do Município de Araçatuba-SP.
O objetivo do presente estudo consiste em descrever o perfil dos acidentes de trabalho ocorridos no município de Araçatuba-SP nos anos de 2000 e 2001. Para tanto, foram analisadas as Comunicações de Acidentes de Trabalho (CATs) emitidas no referido período e as informações pertinentes transcritas em formulário específico elaborado através do programa estatístico Epi-Info versão 6.04, utilizado para tabulação e análise dos dados obtidos. Foram analisadas 772 CATs, das quais 656 correspondiam à ocorrência de acidentes típicos, 92 a acidentes de trajeto e 24 a doenças ocupacionais. A média de idade dos acidentados foi de 32,42 anos (d.p. 10,88) e o tempo médio trabalhado até o momento do acidente foi de 4,15 horas (d.p. 2,73). Quanto ao gênero, 632 acidentes $(81,9 \%$ ) ocorreram com trabaIhadores do sexo masculino e $140(18,1 \%)$ com trabalhadores do sexo feminino. O presente estudo revela um amplo predomínio de acidentes de trabalho classificados como típicos, além de uma maior prevalência em trabalhadores do sexo masculino.

Palavras-chave: acidentes de trabalho; saúde ocupacional; notificação de acidentes de trabalho.

The aim of this study consists in describing the profile of the work accidents occurred at Araçatuba-SP municipality between year 2000 and 2001. For this, Communications of Work Accidents (CAT) emitted during this period were analyzed, as well as the pertinent information transcribed in specific formulary that was designed by a statistic software EpiInfo version 6.04, used for the organization and the analysis of the data. Seven hundreds and seventy two CAT were analyzed, from which 656 corresponded to the occurrence of typical accidents, 92 to path accidents and 24 to occupational diseases. The average of the age of the victims was 32.42 years $(S D=10.88)$ and the average of working time until the moment of the accidents was 4.15 hours $(S D=2.73)$. With regard to the gender, 632 accidents $(81.9 \%)$ occurred with male workers, and 140 (18.1\%) with female workers. The present study shows a high prevalence of work accidents classified as typical, in addition to a higher prevalence among male workers.

Keywords: work accidents; occupational health; occupational accidents registry. 


\section{Introdução}

Este início de novo século está sendo caracterizado pela sedimentação de novas regras regulamentadoras do mercado, em que a produtividade assume papel relevante. Novas formas de produção, viabilizadas pelos avanços tecnológicos e por inovações no modo de organizar e gerir o trabalho, que têm uma abrangência global, vêm introduzindo mudanças radicais na vida e nas relações das pessoas e dos países e, por conseqüência, no viver e adoecer das pessoas. Este processo de reestruturação produtiva tem modificado substancialmente o perfil do trabalho e dos trabalhadores, seus determinantes de saúde-doença, seu quadro epidemiológico, assim como as práticas de saúde voltadas para o trabalhador.

Os acidentes de trabalho figuram neste contexto como um subproduto do sistema de produção moderno, acometendo muitos trabaIhadores no Brasil e no mundo, rompendo o equilíbrio saúde-produtividade, acarretando prejuízos para o próprio trabalhador, para a empresa e para a nação como um todo.

Do ponto de vista legal, acidente de trabatho "é aquele que ocorre pelo exercício do trabalho a serviço da empresa, provocando lesão corporal ou perturbação funcional que cause morte, perda ou redução, permanente ou temporária, da capacidade de trabalho" (Brasil, 1997).

Devido à elevada prevalência e gravidade dos acidentes de trabalho (Brasil, 2002), estes devem ser tratados como um problema de saúde pública, uma vez que suas repercussões não se limitam somente ao processo produtivo, indo muito além, afetando a sociedade como um todo.

Assim, considera-se que compete ao setor de saúde proporcionar condições a um planejamento e à implementação de ações articuladas com os demais setores da sociedade em prol da prevenção e conseqüente redução do número de acidentes de trabalho e sua gravidade.

O objetivo deste estudo consiste em descrever o perfil dos acidentes de trabalho ocorridos no município de Araçatuba-SP, nos anos de 2000 e 2001, e captados pelo sistema de registro do Instituto Nacional do Seguro Social (INSS), visando contribuir para a elabo- ração de políticas de saúde locais que previnam sua ocorrência e reduzam sua gravidade.

\section{Materiais e métodos}

O presente trabalho caracteriza-se como sendo um estudo transversal descritivo (Triviños, 1987) no qual foram analisadas as Comunicações de Acidentes de Trabalho (CATs) emitidas nos anos de 2000 e 2001 no município de Araçatuba-SP. Trata-se de um município localizado no oeste do estado de São Paulo com uma área de $1.167 \mathrm{~km}^{2}$ e população de, aproximadamente, 170 mil habitantes (IBGE, 2000).

A CAT é um documento de emissão obrigatória para trabalhadores cobertos pelo seguro acidentário da Previdência Social. Apesar desta obrigatoriedade, a sub-notificação, particularmente em casos de acidentes de menor gravidade, constitui um problema ainda não solucionado e que acarreta vieses nos sistemas de informação epidemiológica a respeito da ocorrência/prevalência de acidentes de trabalho (Almeida et al., 1993; Barata et al., 2000; Binder et al., 2001).

As CATs contêm informações referentes à identificação do trabalhador acidentado, como idade, gênero, estado civil, bem como horário de ocorrência do acidente, tempo trabalhado até o momento do acidente, ramo de atividade da empresa, ocupação do acidentado, agente causador, natureza e localização da lesão, período estimado de afastamento e local do primeiro atendimento.

As informações supra-relatadas foram transcritas em formulário específico elaborado no programa estatístico Epi-Info versão 6.04, utilizado para análise estatística dos dados obtidos (Dean, 1990).

Vale ressaltar que todas as fases deste estudo foram submetidas à aprovação do Comitê de Ética em Pesquisa, conforme resolução 196/96 (Processo FOA 2002/00866).

\section{Resultados}

Foram registrados 772 acidentes de trabaTho no período estudado, sendo que 345 acidentes $(44,69 \%)$ ocorreram no ano de 2000 e 427 acidentes (55,31\%), no ano de 2001. Nesse mesmo período foram registrados dois óbitos decorrentes de acidentes 
de trabalho, o que pode não ser estatisticamente significante, contudo, tratando-se de vidas humanas, este fato é altamente relevante.

A média de idade dos trabalhadores acidentados ficou em 32,42 anos (d.p. 10,88). Quanto ao gênero, 632 acidentes de trabaIho $(81,9 \%)$ ocorreram com trabalhadores do sexo masculino e $140(18,1 \%)$ com trabalhadores do sexo feminino.

Dos acidentes de trabalho ocorridos nos anos de 2000 e 2001, 656 (85,0\%) caracterizam-se como acidentes típicos, $92(11,9 \%)$ como acidentes de trajeto e $24(3,1 \%)$ como doenças ocupacionais. Quanto ao setor produtivo, $86(11,1 \%)$ dos acidentes ocorreram com trabalhadores do setor primário, 306 $(39,6 \%)$ com trabalhadores do setor secundário e $380(49,2 \%)$ com trabalhadores do setor terciário.

O tempo médio trabalhado até o momento do acidente ficou em 4,15 horas (d.p. 2,73). A respeito desta variável, pode-se observar uma ocorrência maior nas primeiras horas de cada turno de trabalho, como mostra o Gráfico 1.

Gráfico 1 Freqüência de acidentes de trabalho de acordo com o número de horas trabalhadas.

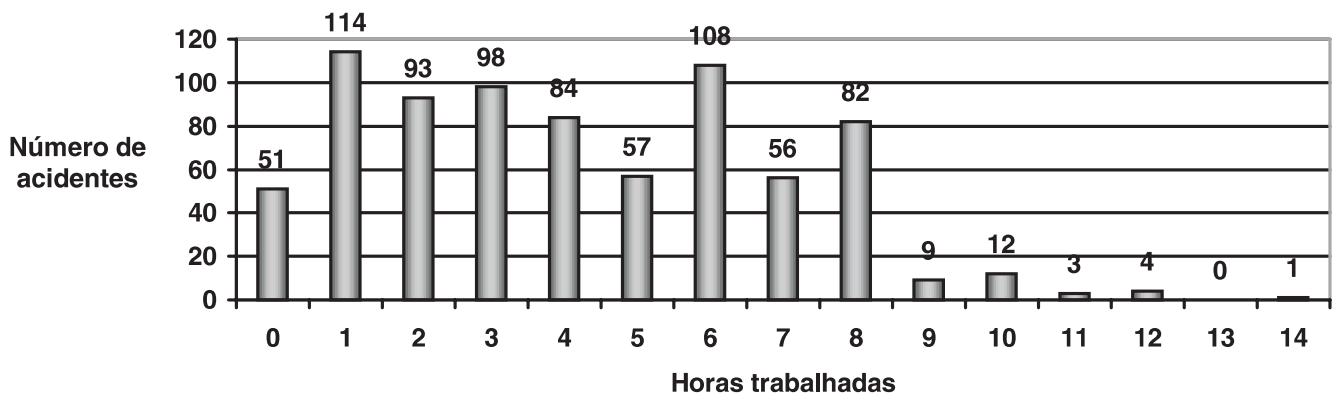

Na maioria dos casos de acidentes de trabalho $(50,4 \%)$, o tempo estimado de afastamento do trabalhador de suas funções foi inferior a sete dias, em somente $19,6 \%$ dos acidentes ocorridos, o período estimado de afastamento foi superior a 15 dias.
A Tabela 2 mostra a distribuição dos acidentados segundo a localização da lesão. Cabe ressaltar que dos 374 acidentes de trabalho que acometeram os membros superiores, $243(64,97 \%)$ atingiram dedos e mãos.

Tabela 2 Distribuição dos acidentes de trabalho segundo a localização da lesão.

\begin{tabular}{l|c|c}
\hline Localização da lesão & Acidentados & Freqüência (\%) \\
\hline Membros superiores & 374 & 48,44 \\
\hline Membros inferiores & 179 & 23,20 \\
\hline Sistemas e aparelhos & 89 & 11,53 \\
\hline Cabeça & 72 & 9,32 \\
\hline Tronco & 39 & 5,05 \\
\hline Pescoço & 5 & 0,65 \\
\hline Múltiplas localizações & 14 & 1,81 \\
\hline Total & 772 & 100,00 \\
\hline
\end{tabular}

A Tabela 3 distribui os acidentes de trabaIho segundo os fatores envolvidos na ocorrência imediata dos mesmos. Pode-se obser- var um predomínio de acidentes de trabalho envolvendo objetos perfurocortantes $(24,5 \%)$ e queda do trabalhador $(22,4 \%)$. 
Tabela 3 Distribuição dos acidentes de trabalho segundo fatores relacionados ao processo causal.

\begin{tabular}{l|c|c}
\hline Fatores do processo causal & Acidentes & Freqüência (\%) \\
\hline Objeto perfurocortante & 190 & 24,6 \\
\hline Queda & 173 & 22,4 \\
\hline Prensa & 92 & 11,9 \\
\hline Corpo estranho & 82 & 10,7 \\
\hline Colisão & 54 & 7,0 \\
\hline Queda de objeto & 52 & 6,7 \\
\hline Esforço físico excessivo & 44 & 5,7 \\
\hline Queimaduras & 33 & 4,2 \\
\hline Choque com objeto & 27 & 3,5 \\
\hline Atropelamento & 13 & 1,7 \\
\hline Agressão & 12 & 1,6 \\
\hline Total & 772 & 100,0 \\
\hline
\end{tabular}

\section{Discussão}

Os resultados obtidos revelam um perfil de acidentados composto por trabalhadores jovens, resultado este semelhante ao encontrado por Almeida et al. (1993), em estudo realizado no município de Botucatu-SP, e Souza et al. (2002), em pesquisa realizada no município de Lages-SC.

Outro resultado encontrado em nosso estudo que se assemelha ao demais trabalhos publicados (Santos et al., 1990; Almeida et al., 1993; Barata et al., 2000; Binder et al., 2001) é um amplo predomínio - superior a $80 \%$ - de acidentes típicos, comparando-se com acidentes de trajeto e doenças ocupacionais. Contudo, estes últimos não devem ser, em hipótese alguma, excluídos dos programas de atenção em saúde do trabalhador.

O predomínio de ocorrência de acidentes com trabalhadores do gênero masculino encontrado em nosso estudo também fora constatado por outros autores (Santos et al., 1990; Almeida et al., 1993). Tal fenômeno pode ser explicado pela natureza da ocupação do gênero masculino, que apresenta um risco maior, aliada ao fato de um maior número de trabalhadores formais pertencerem a este gênero.

Analisando os setores da economia, Binder et al. (2001) encontraram um predomínio de acidentes de trabalho relacionados ao setor secundário, ao passo que, em nosso estudo, o setor produtivo que apresentou maior prevalência de acidentes de trabalho foi o setor terciário. Tal fato pode estar associado ao predomínio de diferentes atividades econômicas nas populações-alvo dos estudos.

Com relação ao tempo trabalhado e ao momento do acidente, observa-se uma tendência decrescente, exceção feita às $6^{\underline{a}}$ e $8^{\mathrm{a}}$ horas, resultados semelhantes aos descritos por Almeida et al., em 1993, e por Souza et al., em 2002.

Avaliando a distribuição dos acidentes de trabalho segundo a localização da lesão, observa-se que aproximadamente metade das ocorrências ocasionou lesão em membros superiores e, destas, $2 / 3$ atingiram a extremidade dos referidos membros - mãos e dedos. Estes números justificam a adoção de medidas preventivas que visem à diminuição destes agravos.

Especial atenção deve ser destinada aos dois principais fatores relacionados ao processo causal dos acidentes de trabalho pesquisados: objetos perfurocortantes e quedas de trabaIhadores. Estratégias devem ser elaboradas e implantadas observando essas variáveis, visando a uma redução na ocorrência de acidentes de trabalho que envolvam esses fatores.

Em recente estudo realizado pela Comissão Técnica de Segurança de Acidentes de Trabalho e Enfermidades Profissionais da Associação Internacional de Seguridade So- 
cial (Schubert, 2001), a insuficiência, escassez ou falta de medidas e ações preventivas nesta área foram o resultado apontado por mais de $50 \%$ dos países pesquisados, demonstrando a real necessidade de planejamento $e$ implantação de programas preventivos na área da saúde do trabalhador, inclusive visando a uma redução na ocorrência de acidentes de trabalho.

Ainda a respeito dos programas e das estratégias desenvolvidos na área da saúde do trabalhador, de modo especial àqueles que intencionam uma redução no número e nas seqüelas dos acidentes de trabalho, consideramos que devem ser desenvolvidos através de uma abordagem transdisciplinar e multiprofissional, pautadas na promoção, na proteção, na recuperação e na reabilitação da saúde dos trabalhadores, premissas contidas na conceituação de saúde do trabalhador elaborada pelo Ministério do Trabalho (Brasil, 2001).

Alguns pontos devem ser levados em consideração ao se efetuar a interpretação dos resultados, entre eles, a já mencionada subnotificação que acomete os sistemas de registro e, em segundo lugar, como ressaltaram Sampaio et al. (1998), há de se levar em consideração que os dados coletados referem-se somente aos trabalhadores assalariados. Portanto, desconhece-se o que ocorre, em termos de acidentes de trabalho, ao grupo de trabalhadores autônomos ou informais.

\section{Conclusões}

Em face aos resultados obtidos e com base na revista da literatura, parece-nos pertinente concluir que:

- Houve amplo predomínio de ocorrência de acidentes típicos em comparação com acidentes de trajeto e doenças ocupacionais;

- Em relação ao gênero do acidentado, a prevalência é 4,5 vezes maior no gênero masculino que no feminino;

- A média de idade dos trabalhadores acidentados foi de 32,42 anos;

- O pico de ocorrência de acidentes de trabalho foi na primeira hora trabalhada;

- Os membros superiores foram as regiões mais afetadas em virtude da ocorrência de acidentes de trabalho;

- Programas que visem a uma redução do número dos acidentes de trabalho e à minimização de suas seqüelas devem destinar atenção especial aos fatores desencadeantes mais prevalentes, neste caso, acidentes envolvendo objetos perfurocortantes e quedas dos trabalhadores.

\section{Agradecimento}

À Fundação para o Desenvolvimento da UNESP - FUNDUNESP - pelo auxílio disponibilizado à realização deste estudo.

\section{Referências Bibliográficas}

ALMEIDA, I. M.; BINDER, M. C. P.; \& TOLOSA, D. E. R. Acidentes de trabalho no município de Botucatu-SP, 1990. Revista Brasileira de Saúde Ocupacional, v. 21, n. 80, 29-43, 1993.

BARATA, R. C. B.; RIBEIRO, M. C. S. A.; \& MORAES, J. C. Acidentes de trabalho referidos por trabalhadores moradores em área urbana no interior do estado de São Paulo em 1994. Informe Epidemiológico do SUS, v. 9, n. 3, 199-210, 2000.

BINDER, M. C. P.; WLUDARSKI; S. L.; \& ALMEIDA, I. M. Estudo da evolução dos acidentes de trabalho registrados pela Previdência Social no período de 1995 a
1999, em Botucatu, São Paulo. Cadernos de Saúde Pública, v. 17, n. 4, 915924, 2001.

BRASIL. Ministério da Previdência Social. Os números de acidentes do trabalho no Brasil-1996/98. Disponível on line: <http:/ /www.mpas.gov.br/ 12_05.htm> Acesso em: 17/06/2002.

Ministério da Previdência Social. Regulamento dos benefícios da previdência social: Decreto 2.172/97. Brasília, 1997.

Ministério da Saúde. Programa de Saúde do Trabalhador - Apresentação. Brasília, 2001. 
DEAN, A. G. et al. Epi Info, Version 5: a word processing, database, and statistics program for epidemiology on microcomputers. Centers for Disease Control. Atlanta, Georgia, USA, 1990.

SAMPAIO, R. F. et al. Acidentes de trabalho em Barcelona (Espanha), no período de 1992-1993. Revista de Saúde Pública, v. 32, n. 4, 345-351, 1998.

SANTOS, U. P. et al. Sistema de vigilância epidemiológica para acidentes de trabalho: experiência na zona norte do município de São Paulo (Brasil). Revista de Saúde Pública, v. 24, n. 4, 286-293, 1990.
SCHUBERT, B. Problemas actuales del seguro obligatorio de accidentes a escala mundial: una encuesta de la AISS. Suécia, 2001. 18p.

SOUZA, V.; BLANK, V. L. G.; \& CALVO, M. C. M. Cenários típicos de lesões decorrentes de acidentes de trabalho na indústria madeireira. Revista de Saúde Pública, v. 36, n. 6, 702-708, 2002.

TRIVIÑOS, A. N. S. Introdução à pesquisa em ciências sociais: a pesquisa qualitativa em educação. São Paulo: Atlas, 1987. 175p. 